\title{
Spanish Experience in Autologous Chondrocyte Implantation
}

\author{
Santiago Pérez-Cachafeiro ${ }^{1}$, Alberto Ruano-Raviña ${ }^{1,2}$, José Couceiro-Follente ${ }^{3}$, \\ Jose Antonio Benedí-Alcaine ${ }^{4}$, Ignacio Nebot-Sanchis ${ }^{5}$, Ciriaco Casquete-Román ${ }^{1}$, \\ Santiago Bello-Prats ${ }^{6}$, Gonzalo Couceiro-Sánchez ${ }^{7}$, Francisco J. Blanco ${ }^{*}, 8$ \\ ${ }^{I}$ Galician Agency for Health Technology Assessment, Santiago de Compostela, Spain \\ ${ }^{2}$ Department of Preventive Medicine and Public Health, Santiago de Compostela University, Spain \\ ${ }^{3}$ Orthopaedic Department, Santiago de Compostela University Hospital, Spain \\ ${ }^{4}$ Orthopaedic Department, Miguel Servet University Hospital, Zaragoza, Spain \\ ${ }^{5}$ Orthopaedic Department, Dr. Peset Hospital, Valencia, Spain \\ ${ }^{6}$ Orthopaedic Department, La Paz Hospital, Madrid, Spain \\ ${ }^{7}$ Orthopaedic Department, Santa Teresa Hospital, A Coruña, Spain \\ ${ }^{8}$ Rheumatology Unit, Cartilage Research Unit, Hospital Juan Canalejo, A Coruña, Spain
}

\begin{abstract}
Introduction: The Spanish Ministry of Health commissioned the Galician Agency for Health Technology Assessment to monitor and follow-up Autologous Chondrocyte Implantation (ACI) used to treat chondral lesions of the knee in Spain. The objective of this monitoring was to assess efficacy and safety of the technique.

Design: One-hundred and eleven consecutive patients with knee chondral lesions were included in a multi-center study between January 2001 and January 2005. ACI was used in these patients as a second-line treatment option (or a first-line treatment option if the cause was Osteocondritis dissecans). The Cincinnati score and the Short Form 36 (SF-36) questionnaire were used to assess the patients' self-reported satisfaction with the outcomes of ACI. A descriptive analysis was performed and non-parametric tests were used to establish correlations and compare results among subgroups. A multivariate analysis was also performed to measure the effect of different variables on changes in the condition of the knee.

Results: Eighty men (72\%) and 31 women (21\%) with an age range from 16 to 49 years, underwent ACI surgery. Among these subjects, the most common previous first-line treatment was debridement (64 individuals, 74.4\%). The mean size of the lesion treated with ACI was $3.82 \mathrm{~cm}^{2}$, and the most frequent location of the lesion was the inner femoral condyle (53.6\%). The patient satisfaction was high or very high in 36 subjects $(66.7 \%)$. Overall knee joint assessment improved from 4.32 points to 6.78 . All SF-36 questionnaire categories improved, notably those related to physical condition.

Conclusions: The results of this study indicate that ACI is safe; however, further studies are mandated to assess the efficacy of ACI compared to alternative treatment options.
\end{abstract}

Keywords: Chondrocytes, cartilage, clinical trial, implantation, ACI, transplant.

\section{INTRODUCTION}

The actual incidence of knee cartilage injuries is unknown, partly because of the gap between occurrence of the primary lesion and the onset of symptoms [1]. According to previous studies, the prevalence of knee chondral lesions is estimated to be $60-63 \%$ of the population undergo arthroscopy. The medial femoral condyle and patella are the most commonly injured sites [2,3].

Several surgical procedures have been developed to treat chondral lesions $[4,5]$. The primary aim of these techniques is to stop or delay the progression of cartilage degeneration

*Address correspondence to this author at the INIBIC-Hospital Universitario A Coruña, 15006- A Coruña, Spain;

E-mail: francisco.blanco.garcia@sergas.es to osteoarthritis. Secondary objectives of these therapies are regeneration of the cartilage itself and decreasing the need for articular replacements. The procedures can be classified into four general categories: (a) symptomatic treatment, (b) stimulation of bone marrow, (c) chondrogenesis of tissue cells, and (d) transplantation of osteochondral plugs [6].

One of the chondrogenesis techniques used is autologous chondrocyte implantation (ACI). This is a two-step procedure. First, normal cartilage tissue cells are extracted from a non-weight-bearing area of the knee. These isolated cartilage cells are cultured and then implanted onto the chondral defect. Classically, a periosteum cover is used to retain the implant in situ. Newer variations of ACI use collagenous membranes or a laboratory-formed matrix to keep the cell transplant in place [7-9]. 
In this paper, we present a Spanish multi-center case series with five years of follow-up. The objectives of this study are to assess the safety of ACI and its efficacy in terms of clinical outcomes, quality of life and patient satisfaction.

\section{SUBJECTS AND METHODS}

\section{Setting}

An agreement between the Spanish Ministry of Health and Regional Departments of Health commissioned the Galician Agency for Health Technology Assessment (AVALIA-t) to monitor and follow-up ACI procedures in Spain. The aim of this monitoring (known as tutelage) was to assess the efficacy and safety of the technique in order to consider it for inclusion in the services portfolio of the National Health System. Seven Spanish hospitals collaborated in this study: Santiago de Compostela University Hospital (Santiago de Compostela), Miguel Servet Hospital (Zaragoza), Dr. Peset Hospital (Valencia), Juan Canalejo University Hospital (A Coruña), Río Hortega University Hospital (Valladolid), La Paz Hospital (Madrid), and Santa Teresa Policlinic Institute (A Coruña).

\section{Study Design}

A consensus protocol was developed to perform a prospective follow-up examination of ACI procedures. All consecutive ACI procedures done between April 1, 2001 and January 15, 2005 at a collaborating center were incorporated into the "tutelage". Tutelage modality is an open observational and prospective study supported by de Sapnish Health Government.

Inclusion criteria for this study included: symptomatic lesions involving full knee cartilage thickness, diameter of the defect between 2 and $9 \mathrm{~cm}^{2}$, age of the subject between 18- and 55-years-old, presence of disabling symptoms and failure of other conventional treatments. ACI would therefore be a second-line treatment, except in those subjects diagnosed with Osteocondritis dissecans (OCD) because $\mathrm{ACI}$ is considered to be the first-line treatment for this condition.

Exclusion criteria included: degenerative conditions of the knee associated with osteoarthritis and hypersensitivity to any component of the culture media, such as antibiotics.

After surgery (using periostium to cover the lesion) and chondrocyte implantation, subjects were not given a standardized protocol of physiotherapy. Each hospital used its own protocol for re-establishing knee movement postoperatively.

\section{Data Capture}

Data pertaining to sex, age, occupation, previous surgeries, cause of the lesion, and site of the lesion, concurrent pathologies, physical activity and allergies were collected preoperatively. Arthroscopy provided size measurements and macroscopic assessment of the lesion. Follow-up assessments collected data relative to subject overall satisfaction (graded very high, high, low, very low, and not satisfied at all). Validated questionnaires, such as the Cincinnati knee-evaluation score and Short Form 36 questionnaire (SF-36), were used to retrieve clinical and quality of life assessments.
The Cincinnati questionnaire was collected preoperatively and at standard follow-up intervals of 15 days, 1.5, three and six months, and one, two, three, four and five years. The SF-36 form was filled out preoperatively and at six months and one, three and five years. All data were collected by hospital consultants and sent to avalia-t every six to nine months.

\section{Statistical Analysis}

Data were managed with SPSS 12.0 software (Chicago, USA). The data were first screened to eliminate abnormal values and mistakes produced during the data collection process. A descriptive analysis was performed using SPSS 12.0 and EXCEL software. Non-parametric tests were used to assess correlations (Spearman's rho) and to compare results among subgroups (Mann-Whitney U-test). Subgroups were defined according to the following: fulfilling the inclusion criteria (e.g., some patients underwent ACI without meeting the inclusion criteria), existence of previous surgeries, diagnosis of OCD age (two subgroups were defined as 30-years-old or less and over 30-years-old), and location of the chondral lesion. A multivariate analysis was also performed to measure the impact of different variables on the condition of the knee after ACI.

After analyzing the subgroups, 14 subjects who did not meet the standard inclusion criteria were included in the analysis: some failed to report a previous surgery and others suffered injuries affecting less than $50 \%$ of the cartilage thickness. The decision to retain the data from these subjects was made after demonstrating by subgroup analysis that their results did not differ from the rest.

\section{RESULTS}

\section{Subject Characteristics}

A total of 111 subjects were included from Santiago de Compostela University Hospital (55); Miguel Servet Hospital (22); Dr. Peset Hospital (10); Juan Canalejo University Hospital (9); Río Hortega University Hospital (7); La Paz Hospital (6) and Santa Teresa Policlinic Institute (2). Among the subjects were 80 males $(72.1 \%)$ and 31 females $(29.1 \%)$ (Table 1) with an overall mean age of 30.9 years (95\% confidence interval: 29.1-32.7). The right knee was more frequently affected than the left knee (56\% vs $44 \%)$. Interestingly, $76.5 \%$ of the subjects showed no concurrent pathology and trauma was the most frequent etiology $(30.6 \%)$, (Table 1). OCD was diagnosed in $22.5 \%$ of the subjects (Table 1). Debridement constituted $74.4 \%$ of previous surgeries in those subjects receiving ACI as a second-line therapy. Chondral lesions were more frequent in the medial condyle (53.6\%) (Table 1) and the mean size of the lesions was $3.8 \mathrm{~cm}^{2}$.

The rate of participation by the subjects decreased over the follow-up period, being approximately $65 \%$ at two years, $60 \%$ at three years and $25 \%$ at five years (Table 2 ).

\section{Clinical Efficacy}

The daily activities portion of the Cincinnati questionnaire revealed the following assessment of the knee condition of the subjects (Table 3): $68.9 \%$ of the subjects had no walking limitations, $28 \%$ had mild limitations and 
Table 1. Baseline Characteristics of Subjects Receiving Autologous Chondrocyte Implantation (ACI) to Treat Chondral Lesions of the Knee

\begin{tabular}{|c|c|c|c|}
\hline \multicolumn{2}{|c|}{ Characteristics } & \multirow{2}{*}{$\begin{array}{l}\mathbf{N} \\
80\end{array}$} & \multirow{2}{*}{$\begin{array}{c}\begin{array}{c}\text { Percentages } \\
(\%)\end{array} \\
72.1\end{array}$} \\
\hline Sor & Males & & \\
\hline & Females & 31 & 27.9 \\
\hline \multirow{4}{*}{ Occupation } & Unknown & 25 & 22.5 \\
\hline & Student & 16 & 14.4 \\
\hline & Worker/bricklayer & 11 & 9.9 \\
\hline & Other & 59 & 53.2 \\
\hline \multirow{4}{*}{ Cause of the Lesion } & Unknown & 44 & 39.6 \\
\hline & Traumatic & 34 & 30.6 \\
\hline & Osteocondritis dissecans (OCD) & 25 & 22.5 \\
\hline & Other & 8 & 7.3 \\
\hline \multirow{5}{*}{ Site } & Medial femoral condyle & 59 & 53.6 \\
\hline & Lateral femoral condyle & 8 & 7.2 \\
\hline & Trochlea & 9 & 8.2 \\
\hline & Patella & 18 & 16.4 \\
\hline & Other & 17 & 14.6 \\
\hline
\end{tabular}

only $3.2 \%$ had moderate or severe limitations at three years of follow-up. The stair climbing and descending results showed that $89 \%$ and $100 \%$ of the subjects had no or mild limitations at three and five years, respectively. Severe limitations to kneeling down were also low at three $(13 \%)$ and five years $(0 \%)$ of follow-up. Interestingly, all subjects improved in all aspects of daily activities following ACI (Table 3).

Sporting activity ratings at three years of follow-up showed that $43 \%$ of the subjects had severe or moderate running limitations and $46 \%$ had severe or moderate jumping limitations. However the percentage of subjects with severe limitations to running or jumping was considerably reduced compared with the pre-surgical assessment: running, 54\% vs 15\%; and jumping: 71 vs 31\% (Table 4).

Physical examinations revealed mild to moderate joint effusions in $13.6 \%$ of the subjects after three years, however none were severe and no moderate joint effusions were observed in follow-up years four and five (Table 5). Approximately $10 \%$ of the subjects showed mild to moderate knee flexion or extension reduction at three years follow-up (Table 5).

To perform the subgroup analysis we considered changes in the condition of the knee as a dependent variable. The condition of the knee was measured as the difference between the pre-operative and post-operative follow-up

Table 2. Participation of Subjects Receiving Autologous Chondrocyte Implantation (ACI) to Treat Chondral Lesions of the Knee During the Five-Year Follow-Up

\begin{tabular}{|l|c|c|c|c|c|c|c|c|c|c|}
\hline & Baseline & $\mathbf{1 5} \mathbf{d}$ & $\mathbf{1 . 5} \mathbf{~ m}$ & $\mathbf{3} \mathbf{~ m}$ & $\mathbf{6 ~ m}$ & $\mathbf{1} \mathbf{y}$ & $\mathbf{2} \mathbf{y}$ & $\mathbf{3} \mathbf{y}$ & $\mathbf{4} \mathbf{y}$ & $\mathbf{5} \mathbf{y}$ \\
\hline \hline Expected Cases & 111 & 110 & 110 & 110 & 110 & 110 & 110 & 98 & 71 & 25 \\
\hline Analysed Cases* & 110 & 52 & 81 & 98 & 96 & 92 & 71 & 61 & 12 & 6 \\
\hline Percentage of Analysed Cases (\%) & 99.1 & 47.3 & 73.6 & 89.1 & 87.3 & 83.6 & 64.5 & 62.2 & 16.9 & 24 \\
\hline
\end{tabular}

$\mathrm{d}=$ day; $\mathrm{m}=$ month; $\mathrm{y}=$ year.

*We did not receive preoperative assessment in one case.

Table 3. Cincinnati Questionnaire: Daily Activities of Subjects Receiving Autologous Chondrocyte Implantation (ACI) to Treat Chondral Lesions of the Knee

\begin{tabular}{|c|c|c|c|c|c|c|c|}
\hline Item & Grade of Limitation & Pre-Surgery & 1 Year & 2 Years & 3 Years & 4 Years & 5 Years \\
\hline \multirow{4}{*}{ Walking } & No Limitation & $24.8 \%$ & $48.9 \%$ & $59.2 \%$ & $68.9 \%$ & $75.0 \%$ & $66.7 \%$ \\
\hline & Limitation mild & $41.6 \%$ & $42.4 \%$ & $35.2 \%$ & $27.9 \%$ & $25.0 \%$ & $33.3 \%$ \\
\hline & Limitation moderate & $23.9 \%$ & $8.7 \%$ & $4.2 \%$ & $1.6 \%$ & $0.0 \%$ & $0.0 \%$ \\
\hline & Limitation severe & $9.7 \%$ & $0.0 \%$ & $1.4 \%$ & $1.6 \%$ & $0.0 \%$ & $0.0 \%$ \\
\hline \multirow{4}{*}{ Stair Climbing and Descending } & No Limitation & $16.8 \%$ & $35.2 \%$ & $40.3 \%$ & $42.6 \%$ & $66.7 \%$ & $66.7 \%$ \\
\hline & Limitation mild & $41.6 \%$ & $49.5 \%$ & $50.0 \%$ & $45.9 \%$ & $25.0 \%$ & $33.3 \%$ \\
\hline & Limitation moderate & $17.7 \%$ & $8.8 \%$ & $4.2 \%$ & $6.6 \%$ & $8.3 \%$ & $0.0 \%$ \\
\hline & Limitation severe & $23.9 \%$ & $6.6 \%$ & $5.6 \%$ & $4.9 \%$ & $0.0 \%$ & $0.0 \%$ \\
\hline \multirow{4}{*}{ Kneeling } & No Limitation & $7.9 \%$ & $19.6 \%$ & $20.8 \%$ & $33.3 \%$ & $25.0 \%$ & $66.7 \%$ \\
\hline & Limitation mild & $31.9 \%$ & $52.2 \%$ & $48.6 \%$ & $45.0 \%$ & $50.0 \%$ & $33.3 \%$ \\
\hline & Limitation moderate & $17.7 \%$ & $9.8 \%$ & $15.3 \%$ & $8.3 \%$ & $0.0 \%$ & $0.0 \%$ \\
\hline & Limitation severe & $42.5 \%$ & $18.5 \%$ & $15.3 \%$ & $13.3 \%$ & $25.0 \%$ & $0.0 \%$ \\
\hline
\end{tabular}


Table 4. Cincinnati Questionnaire: Sport Activities in Subjects Receiving Autologous Chondrocyte Implantation (ACI) to Treat Chondral Lesions of the Knee

\begin{tabular}{|c|c|c|c|c|c|c|c|}
\hline Item & Grade of Limitation & Pre-Surgery & 1 Year & 2 Years & 3 Years & 4 Years & 5 Years \\
\hline \multirow{3}{*}{ Running } & No Limitation & $3.5 \%$ & $12.0 \%$ & $15.7 \%$ & $19.7 \%$ & $16.7 \%$ & $33.3 \%$ \\
\hline & Limitation moderate & $20.4 \%$ & $23.9 \%$ & $21.4 \%$ & $27.9 \%$ & $16.7 \%$ & $33.3 \%$ \\
\hline & Limitation severe & $54.0 \%$ & $32.6 \%$ & $27.1 \%$ & $14.8 \%$ & $16.7 \%$ & $0.0 \%$ \\
\hline \multirow{3}{*}{ Jumping } & Limitation mild & $15.2 \%$ & $31.5 \%$ & $40.8 \%$ & $36.1 \%$ & $58.3 \%$ & $66.7 \%$ \\
\hline & Limitation moderate & $10.7 \%$ & $18.5 \%$ & $12.7 \%$ & $14.8 \%$ & $16.7 \%$ & $0.0 \%$ \\
\hline & Limitation severe & $70.5 \%$ & $42.4 \%$ & $36.6 \%$ & $31.1 \%$ & $8.3 \%$ & $0.0 \%$ \\
\hline Twisting & No Limitation & $4.4 \%$ & $8.8 \%$ & $8.5 \%$ & $16.4 \%$ & $16.7 \%$ & $33.3 \%$ \\
\hline
\end{tabular}

Table 5. Cincinnati Questionnaire: Physical Examinations of Subjects Receiving Autologous Chondrocyte Implantation (ACI) to Treat Chondral Lesions of the Knee

\begin{tabular}{|c|c|c|c|c|c|c|c|}
\hline Item & Grade of Limitation & Pre-Surgery & 1 Year & 2 Years & 3 Years & 4 Years & 5 Years \\
\hline \multirow{4}{*}{ Joint Effusion } & No Limitation & $73.2 \%$ & $93.3 \%$ & $91.3 \%$ & $86.4 \%$ & $75.0 \%$ & $50.0 \%$ \\
\hline & Limitation mild & $22.6 \%$ & $6.7 \%$ & $7.2 \%$ & $11.9 \%$ & $25.0 \%$ & $50.0 \%$ \\
\hline & Limitation moderate & $2.1 \%$ & $0.0 \%$ & $1.4 \%$ & $1.7 \%$ & $0.0 \%$ & $0.0 \%$ \\
\hline & Limitation severe & $2.1 \%$ & $0.0 \%$ & $0.0 \%$ & $0.0 \%$ & $0.0 \%$ & $0.0 \%$ \\
\hline \multirow{4}{*}{ Reduction of Flexion } & No Limitation & $82.0 \%$ & $90.0 \%$ & $92.8 \%$ & $89.8 \%$ & $91.7 \%$ & $83.3 \%$ \\
\hline & Limitation mild & $9.5 \%$ & $5.6 \%$ & $4.3 \%$ & $6.8 \%$ & $8.3 \%$ & $16.7 \%$ \\
\hline & Limitation moderate & $5.3 \%$ & $3.3 \%$ & $2.9 \%$ & $3.4 \%$ & $0.0 \%$ & $0.0 \%$ \\
\hline & Limitation severe & $3.2 \%$ & $1.1 \%$ & $0.0 \%$ & $0.0 \%$ & $0.0 \%$ & $0.0 \%$ \\
\hline \multirow{4}{*}{ Reduction of Extension } & No Limitation & $88.3 \%$ & $92.1 \%$ & $97.1 \%$ & $89.8 \%$ & $100 \%$ & $100 \%$ \\
\hline & Limitation mild & $7.4 \%$ & $5.6 \%$ & $2.9 \%$ & $10.2 \%$ & $0.0 \%$ & $0.0 \%$ \\
\hline & Limitation moderate & $3.2 \%$ & $2.2 \%$ & $0.0 \%$ & $0.0 \%$ & $0.0 \%$ & $0.0 \%$ \\
\hline & Limitation severe & $1.1 \%$ & $0.0 \%$ & $0.0 \%$ & $0.0 \%$ & $0.0 \%$ & $0.0 \%$ \\
\hline
\end{tabular}

assessments. At three years of follow-up, this subgroup analysis found no differences related to the fulfilment of the inclusion criteria, presence of associated pathologies, site of the lesion, or presence of OCD (Fig. 1). A significant association was found between age and the condition of the knee $(\mathrm{p}=0.046)$ when we compared subjects less than or equal to 30 -years-old with subjects greater than 30-years-old, which suggests poorer outcomes for older patients (Fig. 1). We also found a significant difference related to knee condition between subjects with previous surgeries and those with no earlier surgery; knees not undergoing previous surgery had better outcomes $(p=0.041)$ (Fig. 1). No significant differences were obtained at four and five years of follow-up because of the limited number of observations (Table 2). Fig. (1) shows some of the trends revealed by subgroup analysis.

\section{Patient Satisfaction and Quality of Life}

The results of questions regarding pain, swelling, blockage of knee and general condition of the knee, according to the Cincinnati questionnaire, demonstrated that the outcomes were favourable. The poorest values (2-3 points) were present at 15 days after surgery; however, after three and five years follow-up, the results (7-10 points) showed a nearly normal knee (Fig. 2). Self-assessed subject satisfaction was rated as high or very high by $67.4 \%$ of the subjects at the one year follow-up, $71.2 \%$ at two years, $66.6 \%$ at three years, $90.9 \%$ at four years and $50.0 \%$ at five years (Table 6).

In addition, the quality of life of the subjects, as reflected by the SF-36 questionnaires increased throughout the followup period. The most improved paramenters were physical 


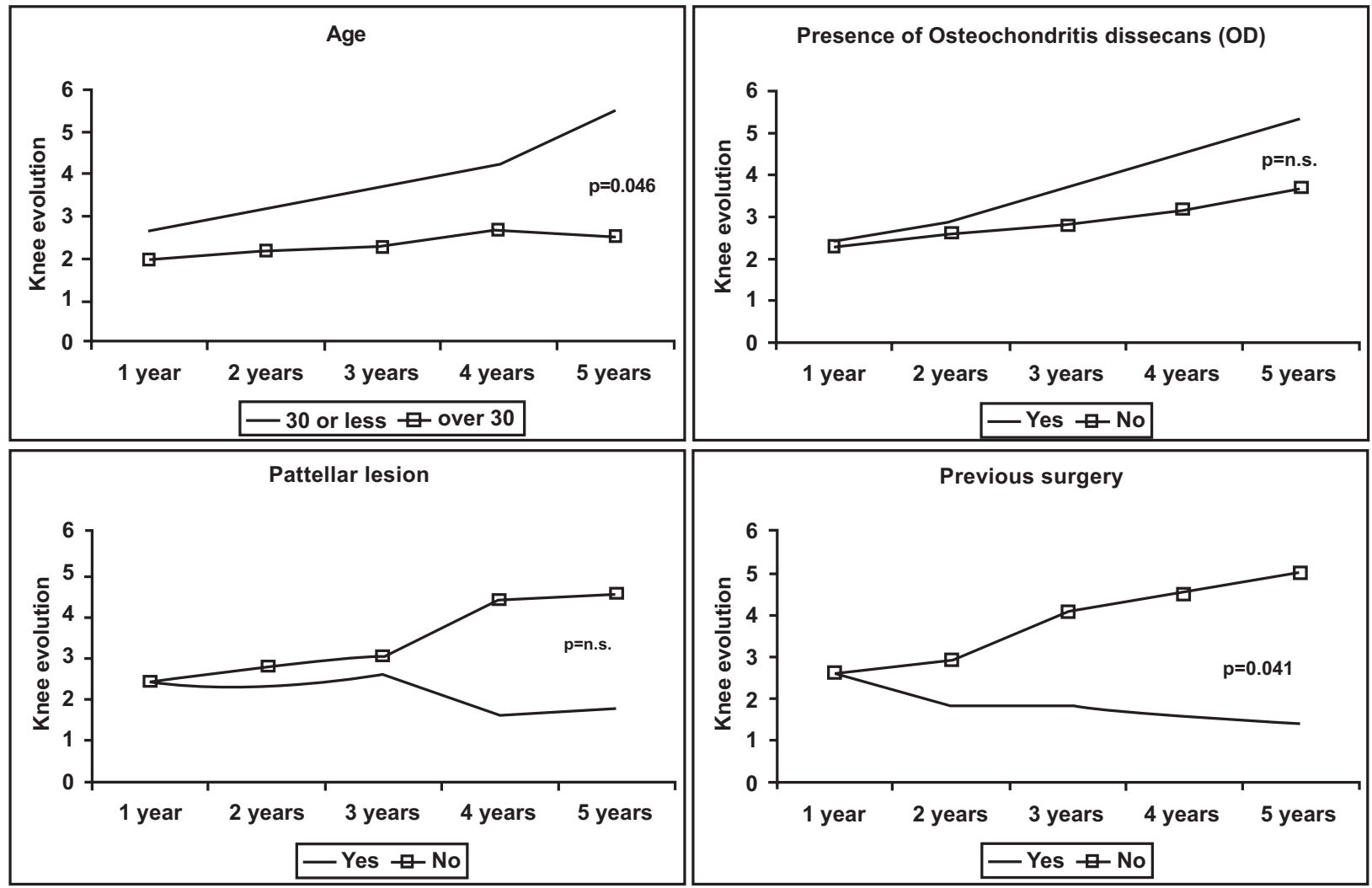

Fig. (1). Development of pain, swelling, and blockage according to Cincinnati questionnaires.

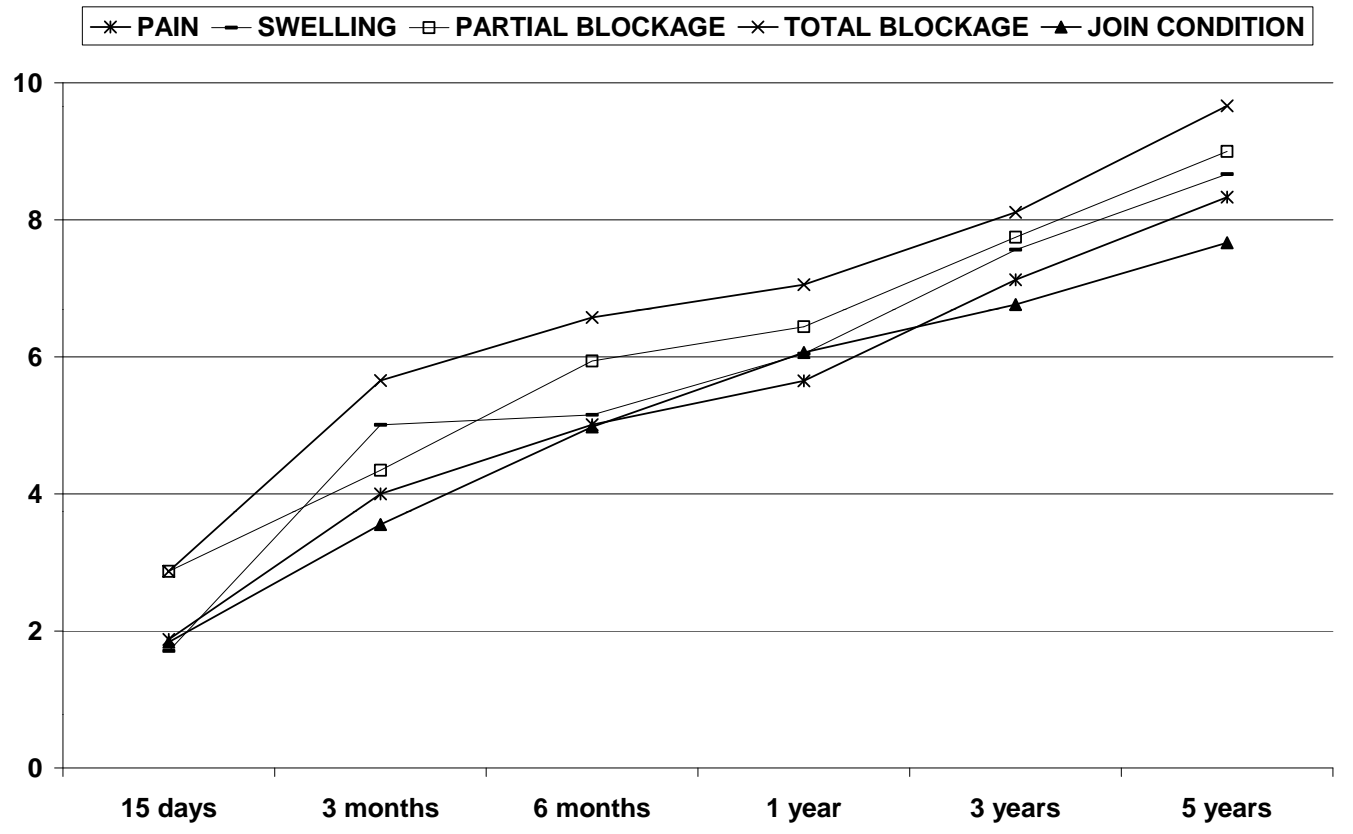

Fig. (2). Subgroup analysis.

role and physical function, while mental health showed the least improvement (Fig. 3).

\section{Adverse Events}

The incidence of reported adverse events was low. During the first year, 19 adverse events were reported including joint effusions (9), infections (4), blockages (3), patellar misalignment (1), displaced grafts (1) and adhesions (1). Treatment was necessary for 18 of these subjects and additional surgery was needed in eight cases. During the second year, two adverse events occurred related to mild to moderate pain. Five further pain episodes were treated in the 
Table 6. Patient Self-Assessment of Grade of Satisfaction of Subjects Receiving Autologous Chondrocyte Implantation (ACI) to Treat Chondral Lesions of the Knee

\begin{tabular}{|l|c|c|c|c|c|}
\hline \multicolumn{1}{|c|}{ Grade of Satisfaction } & 1 Year & 2 Years & 3 Years & 4 Years & 5 Years \\
\hline \hline Very High & $19.1 \%$ & $27.3 \%$ & $33.3 \%$ & $27.3 \%$ & $25.0 \%$ \\
\hline High & $48.3 \%$ & $43.9 \%$ & $33.3 \%$ & $63.6 \%$ & $25.0 \%$ \\
\hline Low & $24.7 \%$ & $22.7 \%$ & $29.6 \%$ & $9.1 \%$ & $50.0 \%$ \\
\hline Very Low & $3.4 \%$ & $6.1 \%$ & $3.7 \%$ & $0.0 \%$ & $0.0 \%$ \\
\hline None & $4.5 \%$ & $0.0 \%$ & $0.0 \%$ & $0.0 \%$ & $0.0 \%$ \\
\hline
\end{tabular}

\begin{tabular}{llll|}
$\rightarrow-$ Physical function & $\leftarrow$ Physical role & $\rightarrow$ Body pain & $-\cdots$ General health \\
$\rightarrow-$ Vitality & $\rightarrow-$ Social function & $\rightarrow$ Emotional role & $\rightarrow$ Mental health \\
\hline
\end{tabular}

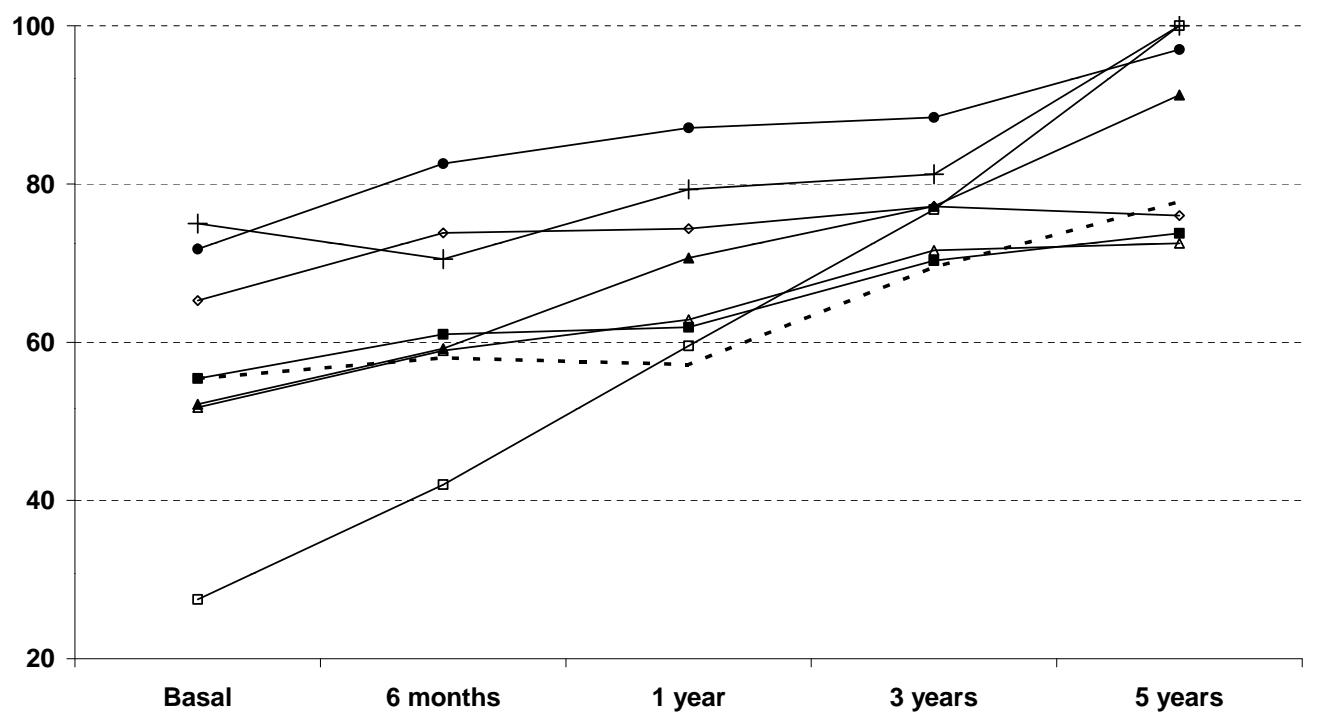

Fig. (3). Changes in SF-36 items.

third year of follow-up; and no adverse events were reported at later follow-ups. No graft failures occurred in the subject group.

\section{DISCUSSION}

This study represents not only the largest Spanish ACI case series, but one of the largest worldwide. The results were influenced by participation rates (Table 2), particularly the number of subjects completing the three, four and five year follow-ups. Overall, high or very high levels of satisfaction were self-reported by $69.6 \%$ of the subjects at their last follow-up (median: 3 years; range: 2-5 years). During the first six months of the study, the activities of the subjects were limited because of rehabilitation protocols; therefore improvements were not considered satisfactory until the first year when Cincinnati scores exceeded 6 . However, clinical improvements progressed throughout the whole follow-up period. Because the number of complications and adverse events reported was relatively low, safety issues were not a concern.

Overall satisfaction levels in our study are slightly lower than those published in previous studies [6]. Peterson et al. obtained high/very high satisfaction in up to $91 \%$ of patients after two years follow-up and in $76 \%$ when they considered a two to nine year interval [10-12]. In a 50 patient caseseries, Micheli et al. found high satisfaction in $83 \%$ of subjects [13]. Because the satisfaction percentages were consistent over time in our study, there may be a group $(30 \%$ of our subjects) resistant to the treatment. However, it is difficult to compare the results of different studies to assess this because the follow-up periods are not uniform. Another possible explanation for our lower percentage of satisfaction may be that ACI was carried out as a second option, and the subjects could have higher expectations for this therapy.

Changes over time in pain, stiffness and blockage were positive. By the first year of follow-up, knee joint condition achieved a value of 6 points ("able to do light work or sports"), representing a good result. After year three, a third of the subjects had moderate to severe limitation in daily activities, such as walking or climbing stairs. This percentage decreased to zero by the fifth year, although about one-third still suffered mild limitations. Fewer restrictions related to sports activities were reported as follow-up time increased. Occupational scores also reflected greater improvement with longer follow-ups.

Knee joint condition improved from 3.72 point preoperatively to 6.1 at one year, 6.4 at two years, 6.8 at three years, 7.4 at four years and 7.7 at five years. These 
results are similar to those of other investigators [12-14]. However, in previously published studies, patients were reported to improve more quickly than in our case-series (joint condition values between 7 and 9 after one to two years of follow-up). This fact could be due to better preoperative conditions in our population and, consequently, to a regression to the mean effect [12].

The subgroup analysis showed an association of better outcomes with younger ages and with no previous surgery. There is a trend (Fig. 2) indicating a possible link between OCD etiology and better outcomes, although this association could be due to the confounding effect of age because patients with OCD tend to be younger. These results are consistent with previous studies that have reported greater improvements in younger patients [15-18]. There are few studies examining the effect of age on results from ACI, in spite of the fact that it appears to be an important variable in determining results.

Even though we anticipated that concurrent pathologies would worsen clinical outcomes, we could not demonstrate this effect. We consider this finding to need further research, because other authors have found better outcomes with isolated lesions [18-20], and the number of subjects with associated pathologies in our series was relatively low.

Quality of life has been reported in only a few studies, in which pain and physical aspects improved the most [21,22]. We found overall improvement in the whole set of aspects evaluated in this questionnaire. Physical role, physical function, body pain and social role showed greater improvements while mental health showed the least improvement.

Nineteen subjects (18\%) were reported to suffer complications during the first year of follow-up. Two additional subjects had experienced adverse events during the second year, and five more by the third year. Leakage $(8.1 \%)$ and infection $(3.6 \%)$ were the commonest adverse events. Other studies have reported higher rates of adverse events, with failure rates between 0 and $7.7 \%$, mainly due to periosteum hypertrophy $[10-14,16,19-21,23]$. A second intervention is required after graft failure. In our series, no failures were reported, although a second intervention was done in a patient with blockage.

Multi-center studies are scarce for procedures like ACI. The multi-centricity with a greater number of patients included in our study provides for increased validity over case studies from a single center. Furthermore, we provide an independent study, whereas most of published studies have conflicts of interest [24]. Although strength of our study is the multi-centre data collection, which provides a relatively large number of subjects, a concern is the lack of standardization of surgical and post-operative rehabilitation protocols, as found with many multi-center studies. The subjects followed a rehabilitation program according to the knee surgery rehabilitation protocol of each hospital. However, some procedures were followed in all the hospitals. Weight-bearing status after surgery was restricted for three to six months and continuous passive motion (CPM) was started 24 hours after surgery and continued throughout hospitalization. Interestingly, although rehabilitation was not standardized, we did not find any large differences in the results from different hospitals. However, inter-hospital differences could explain some of the relatively small differences in patient satisfaction between our study and other reported studies.

A main limitation of our study was the use of a caseseries design. Because of the lack of a control group, it is difficult to obtain causality associations. We, therefore, cannot definitively conclude that ACI is superior to other techniques. We were unable to evaluate the effect of different rehabilitation protocols because of the lack of a standardized protocol. Nevertheless, because clinical outcomes were good, we could consider that adequate rehabilitation protocols were implemented at all participating hospitals.

\section{CONCLUSIONS}

Patients treated by ACI are quite satisfied with their outcomes and report good quality of life after the procedure. Clinical results were good in about $70 \%$ of patients based on their responses to our questionnaires.

Medium-term results (three to five years) show that ACI appears to be safe. The regeneration of hyaline-like cartilage is unknown because we could not obtain biopsies from our patients. Any effect attributable to rehabilitation program differences associated with ACI has not been investigated. In addition, cost appears to be a serious limitation to implementation of this procedure $[25,26]$. The future of ACI depends on further investigations through well-designed randomized trials with long term follow-up. These studies should include the demonstration of cartilage regeneration and reduction of the number of knee replacements in patients undergoing ACI.

\section{ABBREVIATIONS

$\begin{array}{ll}\text { ACI } & \text { Autologous Chondrocyte Implantation } \\ \text { AVALIA-t }= & \text { Galician Agency for Health Technology } \\ & \text { Assessment } \\ \text { CPM } & =\text { Continuous passive motion } \\ \text { OCD } & =\text { Osteocondritis dissecans } \\ \text { SF-36 } & =\text { Short Form } 36 \text { questionnaire }\end{array}$

\section{REFERENCES}

[1] Jobanputra P, Parry D, F-S A, Burls A. Effectiveness of autologous chondrocyte transplantation for hyaline cartilage defects in knees: A rapid and systematic review. Health Technol Assess 2001; 5(11): $1-57$.

[2] Curl W, Crome J, Gordon R, et al. Cartilage injuries: a review of 31.513 knee arthroscopies. Arthroscopy 1997; 13: 456-60.

[3] Hjelle K, Solheim E, Strand T, Muri R, Brittberg M. Articular cartilage defects in 1000 knee arthroscopies. Arthroscopy 2002; 18: 730-4.

[4] Hospodar SJ, Tokish JM. Management of articular cartilage injuries in the knee. Operat Tech Sports Med 2005; 13: 150-6.

[5] Messner K. Repair of articular cartilage lesions. In: Insall JN, Scott WN, Eds. Madrid: Marban 2004; pp. 327-40. Spanish.

[6] Ruano-Ravina A, Diaz MJ. Autologous chondrocyte implantation: A systematic review. Osteoarthr Cartil 2006; 14: 47-51.

[7] Behrens P, Bitter T, Kurz B, Russlies M. Matrix-associated autologous chondrocyte transplantation/implantation (MACT/MACI)5-year follow-up. Knee 2006; 13: 194-202.

[8] Brittberg M, Lindahl A, Nilsson A, et al. Treatment of deep cartilage defects in the knee with autologous chondrocyte transplantation. N Eng J Med 1994; 331(14): 889-95. 
[9] Krishnan SP, Skinner JA, Carrington RW, et al. Collagen-covered autologous chondrocyte implantation for osteochondritis dissecans of the knee: two- to seven-year results. J Bone Joint Surg Br 2006; 88: 203-5.

[10] Peterson L, Brittberg M, Kiviranta I, Akerlund E, Lindahl A. Autologous chondrocyte transplantation. Biomechanics and long term durability. Am J Sports Med 2002; 30: 2-12.

[11] Peterson L, Minas T, Brittberg M, Lindahl A. Treatment of Osteochondritis dissecans of the knee with autologous chondocyte transplantation. J Bone Joint Surg Am 2003; 85-A: S17-24.

[12] Peterson L, Minas T, Brittberg M, et al. Two-to-9-year outcome after autologous chondrocyte transplantation of the knee. Clin Orthop 2000; 374: 212-34.

[13] Micheli LJ, Browne JE, Erggelet C, et al. Autologous chondrocyte implantation of the kne: multicenter experience an minimum 3 year follow-up. Clin J Sport Med 2001; 11: 223-8.

[14] Erggelet C, Steinwachs M, Reichelt A. The operative treatment of full thickness cartilage defects in the knee joint with autologos chondrocyte transplantation. Saudi Med J 2000; 21: 715-21.

[15] Bartlett W, Skinner JA, Gooding CR, et al. Autologous chondrocyte implantation versus matrix-induced autologous chondrocyte implantation for osteochondral defects of the knee. A prospective, randomised study. J Bone Joint Surg - Ser B 2005; 87: 640-5.

[16] Knutsen G, Engebretsen L, Ludvigsen T, et al. Autologous chondrocyte implantation compared with microfracture in the knee: a randomized trial. J Bone Joint Surg Am 2004; 86-A: 455-64.

[17] Mithofer K, Minas T, Peterson L, Yeon H, Micheli LJ. Functional outcome of knee articular cartilage repair in adolescent athletes. Am J Sports Med 2005; 33: 1147-53.

[18] Mithofer K, Peterson L, Mandelbaum BR, Minas T. Articular cartilage repair in soccer players with autologous chondrocyte transplantation: functional outcome and return to competition. Am J Sports Med 2005; 33: 1639-46.

[19] Henderson I, Francisco R, Oakes B, Cameron J. Autologous chondrocyte implantation for treatment of focal chondral defects of the knee - A clinical, arthroscopic, MRI and histologic evaluation at 2 years. Knee 2005; 12: 209-16.

[20] Browne JE, Anderson AF, Arciero R, et al. Clinical outcome of autologous chondrocyte implantation at 5 years in US subjects. Clin Orthop Relat Res 2005; (436): 237-45.

[21] Bartlett W, Gooding CR, Carrington RW, et al. The role of the short form 36 health survey in autologous chondrocyte implantation. Knee 2005; 12: 281-5.

[22] Minas T, Bryant $T$. The role of autologous chondrocyte implantation in the patellofemoral joint. Clin Orthop Relat Res 2005; (436): 30-39.

[23] Fu FH, Zurakowski D, Brown JE, et al. Autologous chondrocyte implantation versus debridement for treatment of full-thickness chondral defects of the knee - An observational cohort study with 3-year follow-up. Am J Sports Med 2005; 33: 1658-66.

[24] Jacobsen R, Engebretsen L, Slauterbeck J. An analysisis of the quality of cartilage repair studies. J Bone Joint Surg Am 2005; 87 : 2232-9.

[25] Clar C, Cummins E, McIntyre L, et al. Clinical and costeffectiveness of autologous chondrocyte implantation for cartilage defects in knee joints: systematic review and economic evaluation. Health Technol Assess 2005; 9: iii-iv, ix-x, 1-82.

[26] Derrett S, Stokes EA, James M, Bartlett W, Bentley G. Cost and health status analysis after autologous chondrocyte implantation and mosaicplasty: a retrospective comparison. Int J Technol Assess Health Care 2005; 21: 359-67.

(C) Pérez-Cachafeiroe et al.; Licensee Bentham Open.

This is an open access article licensed under the terms of the Creative Commons Attribution Non-Commercial License (http://creativecommons.org/licenses/by$\mathrm{nc} / 3.0 /$ ) which permits unrestricted, non-commercial use, distribution and reproduction in any medium, provided the work is properly cited. 